\title{
Развитие приближения Вентцеля-Крамерса-Бриллюэна для ускорения метода дискретных диполей
}

\author{
К.Г. Инжеваткин \\ Институт химической кинетики и горения им. В.В. Воеводского СО РАН \\ Новосибирский государственньй университет \\ E-mail: k.inzhevatkin@yandex.ru
}

DOI: 10.31868/RFL2020.221

Метод дискретных диполей (МДД) предназначен для моделирования рассеяния произвольных гармонических электромагнитных волн на частицах различной формы и внутренней структуры [1]. Отрицательной стороной МДД является значительное время вычислений, что усугубляется частыми требованиями большого количества запусков с различными параметрами рассеивателя. Последнее актуально при решении обратных задач (характеристика отдельной частицы по рассеянному полю), когда используется предварительно рассчитанная база данных индикатрис (до миллиона элементов). В биологических применениях МДД мы обычно имеем дело с большими оптически мягкими частицами, т.е. $|m-1| \ll 1$ и $x \gg 1$, где $m$ - относительный показатель преломления, $x=k R$ - размерный параметр, $k$ - волновой вектор, $R-$ радиус частицы. В связи с этим актуальна задача ускорения МДД для таких частиц. Наиболее трудоемкой частью МДД является решение системы линейных уравнений. Время работы зависит от начального электрического поля внутри частицы, и важно выбрать для него как можно более точный вариант среди тех, которые можно получить с небольшими дополнительными вычислениями.

Для решения данной задачи мы предлагаем модифицированное приближение Венцеля-Крамерса-Бриллюэна (ВКБп). Оно учитывает не только фазовую задержку падающей волны в среде, но и преломление луча на границе рассеивателя. Цель - компенсировать ошибки порядка $x(m-1)^{2}$, поскольку ошибки порядка $x(m-1)$ устраняются стандартным ВКБ [2,3] а обработка ошибок порядка $(m-1)$ потребует полной трассировки лучей. Наш теоретический анализ раскрывает масштабирование различных оптических явлений (преломление, отражение, фокусировка лучей) $\mathrm{c} m$ и $x$, что обосновывает алгоритм ВКБп (добавляются незначительные поправки). Первые результаты моделирования для шаров показывают, что ВКБп работает как задумано (с точки зрения масштабирования), и улучшает как точность внутренних полей, так и время моделирования МДД.

\section{Литература}

[1]. Yurkin M.A., Hoekstra A.G. Journal of Quantitative Spectroscopy and Radiative Transfer. 2007. Vol. 106, № 1-3. P. 558-589.

[2]. Лопатин В.Н., Шепелевич Н.В. Опт. и спектр. 1996. Т. 81, № 1. С. 115-118.

[3]. Klett J.D., Sutherland R.A. Appl. Opt., AO. 1992. Vol. 31, № 3. P. 373-386.

Научный руководитель - канд. физ.-мат. наук М.А. Юркин 